\title{
WHAT DOES INDEPENDENCE MEAN?
}

Those in the field of child and youth care, with its developmental competencies, teach young people to care for themselves and to what extent youth can trust others in healthy relationships as they move towards independence. What does independence mean? Moving towards a mature completion of the developmental challenges of latency age has become far more complicated and tenuous in such complex times.

In Childhood and Society, Erik Erikson contended that youth form their identity in reaction to the historical moment, seek a"moratorium" in which they gain perspective by dropping out, and then emerge as fully formed adults ready to take responsibility. This was certainly true of the "great generation" that went off to war, saw the world, and then came home to build what seemed to be an ever expanding modern industrial base for the country.

However, Arnett and others have noticed that "to be young"today has extended into a whole new developmental stage lasting into the late twenties or even thirties. This stage is replete with exploration of many kinds of careers, avocations, and volunteer experiences. Young adults make temporary commitments to purpose in life- and are often back and forth, between living on their own and cohabitating with their parents. The current economic bifurcation, into rich or poor families, may be responsible for this trend. Unable to find fully paid productive work, young people are likelier to stay with their parents if the family has means, or are forced to stay together if basic resources are scant.

Even college, which was once a ticket to commanding economic independence, can be difficult to access as affirmative action programs have ended. Higher education is also extremely expensive and hard to pay for as the tuition, a kind of entry to sustained middle class, has significantly escalated. Matriculation at a for-profit vocational college also does not guarantee employment in the downturn economy.

For a very limited number of high risk youth, success is guaranteed in higher education. At Geoffrey Canada's Harlem Children's Zone in NYC, comprehensive social supports are added to good schooling for the poorest of the generational poor. The definitive outcome for this intervention can be seen in the large number of children who do eventually go to college and graduate. While admirable, but in short supply, the same can be said for other programs such as the Hershey School, which uses the chocolate fortune to give lifelong economic support to higher education and vocational training. These programs are isolated by the unique circumstances of their extreme cost and are few and far between. However, it does show that when the highest risk youth get what they need, they can succeed.

\section{Teaching Life Skills and Permanency Planning: Two Traditions of Independent Living}

What then for the foster youth who age out of the public welfare system at age eighteen, and the large number of children and youth who grow up in and out of 
residential treatment centers, group homes, and shelter care? The preparation for independent living has two traditions. The first focuses on teaching the everyday life skills necessary for survival. The second emphasizes permanency planning and the development of a network of long term relationships that connect the youth to adults who can continue to support healthy growth throughout their lives. Both are needed more now than ever before.

Skill development in independent living programs is often organized around a curriculum of increasingly complex skills. Such independent living programs focus on maintaining self-care, managing peer relationships, and preparing for work in units that cover time management; preparing a resume and job applications, then seeking and keeping first employment; cooking, cleaning, and doing household routines; budgeting and learning financial literacy; and engaging in clean and sober leisure activities. Perhaps it was always a kind of myth, but in better economic times the gold standard for our youth in independent living was to be able to set an alarm clock to get to work on time, keep a fast food or sales job, finish a GED, and accumulate a closet full of household goods to be ready for moving day. If we are honest, how many of the youth in our care were ever mature and healthy enough to meet those goals? And at 18 years of age, would our own children be ready to live on their own with a one-shot transition from the family home?

\section{Looking to the Future}

As we look to the future, these skills and others are necessary to negotiate life in our current economic downturn. Less hypothetical preparation in which youth role play these skills and more "real work" may be necessary. How can we redesign our independent living programs to be more entrepreneurial and to provide specific apprenticeships and paid vocational experiences? Perhaps the system should be changed —and some jurisdictions have extended care until 21 years of age-so that a youth are not released until they are already working on the job.

It is also true for all youth that the jobs they find may not have existed in their parents' time. Not only will youth need to be prepared to train and retrain into new industries and services, but as young entrepreneurs they will need to know how to access and utilize advancing new technologies and invent and market new products. While this is a far vista from where we stand today, our youth have by and large been failed by their schooling and have grown up in the margins. Entrepreneurism and the new generation of computer-configured businesses are not bound by the same kinds of learning and social structures that have pushed our kids out and away from traditional schooling.

I (Andy) recently watched a homeless street youth, who desperately needed to come into the shelter, instead set the challenge of powerfully and positively panhandling every pedestrian passing until he successfully reached the goal of putting five dollars in his pocket. He said with a wry smile, "never go hungry," and that he would be able to count on having a meal he could purchase himself in the morning. 
With this much determination, guts, and salesmanship, I only hoped that my youth work could find the purpose in this teen to turn such resilience into positive progress towards independent living.

Without a much more entrepreneurial, innovative, and sustained approach, our independent living youth are most vulnerable to becoming a part of the rapidly growing population of adult mentally ill who are living on the streets in structural poverty. We need to rethink the ways in which our youth are strong and the ways in which they will always be challenged - and work together with the youth and society to formulate new programs and organizations to provide far more flexible and adaptable independent living situations.

It's typical today to find that independent living means a practice apartment on campus, a group home satellite to a larger residential program, or a set of classes to be completed after-school. While these formats are not bad and need to be a part of the continuum of care, we see the day when independent living may mean being a part of a lifelong community in which some supports are structured and other needs are met independently. Living communities which revolve around community service and vocational apprenticeships, extended networks of support built into faith-based organizations, service clubs, and unions. Co-housing and other blended experiences in which different periods of life youth might always return "home" to the agency which is their independent living base.

Andrew J. Schneider-Muñoz, EdD, CYC-P

Editor 